\title{
Sex differences in mortality: results from a population-based study of 12 longitudinal cohorts
}

\author{
Yu-Tzu Wu PhD, Albert Sanchez Niubo PhD, Christina Daskalopoulou PhD, Dario Moreno-Agostino PhD, \\ Denes Stefler PhD, Martin Bobak PhD, Sian Oram PhD, Martin Prince MD, Matthew Prina PhD
}

Cite as: CMAJ 2021 March 15;193:E361-70. doi: 10.1503/cmaj.200484

\begin{abstract}
BACKGROUND: Women generally have longer life expectancy than men but have higher levels of disability and morbidity. Few studies have identified factors that explain higher mortality in men. The aim of this study was to identify potential factors contributing to sex differences in mortality at older age and to investigate variation across countries.
\end{abstract}

METHODS: This study included participants age $\geq 50 \mathrm{yr}$ from 28 countries in 12 cohort studies of the Ageing Trajectories of Health: Longitudinal Opportunities and Synergies (ATHLOS) consortium. Using a 2-step individual participant data meta-analysis frame- work, we applied Cox proportional hazards modelling to investigate the association between sex and mortality across different countries. We included socioeconomic (education, wealth), lifestyle (smoking, alcohol consumption), social (marital status, living alone) and health factors (cardiovascular disease, diabetes, mental disorders) as covariates or interaction terms with sex to test whether these factors contributed to the mortality gap between men and women.

RESULTS: The study included 179044 individuals. Men had 60\% higher mortality risk than women after adjust- ment for age (pooled hazard ratio [HR] 1.6; 95\% confidence interval 1.5-1.7), yet the effect sizes varied across countries $\left(I^{2}=71.5 \%\right.$, HR range $\left.1.1-2.4\right)$. Only smoking and cardiovascular diseases substantially attenuated the effect size (by about 22\%).

INTERPRETATION: Lifestyle and health factors may partially account for excess mortality in men compared with women, but residual variation remains unaccounted for. Variation in the effect sizes across countries may indicate contextual factors contributing to gender inequality in specific settings.
$\mathbf{L}$

ife expectancy has increased over the last 6 decades in many societies around the world. ${ }^{1}$ Women generally have longer life expectancy than men, yet have higher levels of disability and morbidity. ${ }^{2,3}$ Male:female mortality ratios increased from the beginning of the 19th century and slightly decreased over the last 3 decades. ${ }^{4,5}$ It has been suggested that the biological differences between the sexes, including genetics and hormones, provide stronger resilience to disadvantageous situations for women than men. ${ }^{6}$ However, biological sex is related to gender, a construct that also incorporates cultural and social differences between men and women. Although some studies suggest that the recent reduction in the male:female mortality ratio is likely a result of improvements in men's health, lifestyle or occupational environments, others attribute it to women's changing societal roles and increasing mortality from diseases such as lung cancer, which have traditionally affected mostly men. ${ }^{3,7-9}$ Many studies have examined the potential impact of social, behavioural and biological factors on sex differences in mortality, ${ }^{10,11}$ but few have been able to investigate potential variation across countries. Different cultural traditions, historical contexts, and economic and societal development may influence gender experiences in different countries, and thus variably affect the health status of men and women.

We aimed to identify factors that may explain the difference in mortality risk between men and women at older age and to investigate potential variation across countries, using the harmonized data set of 12 cohort studies from the Ageing Trajectories of Health: Longitudinal Opportunities and Synergies (ATHLOS) consortium. ${ }^{12}$ 


\section{Methods}

\section{Study population}

The ATHLOS project is a consortium funded by the European Union's Horizon 2020 research and innovation program (grant agreement no. 635316). ${ }^{12}$ The project aims to identify healthy aging trajectories and their determinants, using existing aging cohorts around the world. Most of the ATHLOS cohorts were established after 2000. Researchers in the consortium reviewed information from 17 cohort studies and agreed on approaches to harmonize measures for lifestyle, social environment, physical and psychological health across cohorts.

This study focused on participants aged 50 years or older in the 12 cohort studies with available mortality data, including the 10/66 Dementia Research Group Study (the 10/66 study); ${ }^{13}$ the Australian
Longitudinal Study of Ageing (ALSA): ${ }^{14}$ the ATTICA study; ${ }^{15}$ the China Health and Retirement Longitudinal Study (CHARLS); ${ }^{16}$ the Collaborative Research on Ageing in Europe (COURAGE); ${ }^{17}$ the English Longitudinal Study of Ageing (ELSA); ${ }^{18}$ the Seniors-ENRICA (the Study on Nutrition and Cardiovascular Risk in Spain) study; ${ }^{19}$ the Health, Alcohol and Psychosocial factors In Eastern Europe (HAPIEE) study; ${ }^{20}$ the Health and Retirement Study (HRS); ${ }^{21}$ the Japanese Study of Aging and Retirement (JSTAR);22 the Korean Longitudinal Study of Aging (KLOSA); ${ }^{23}$ and the Survey of Health, Ageing and Retirement in Europe (SHARE). ${ }^{24}$ These 12 cohort studies had recruited community-dwelling older adults from 28 countries (Table 1 ) and used structured interviews to collect individual data. More detailed information on the study population is provided in Appendix 1, Table S1 (available at www.cmaj.ca/lookup/doi/10.1503/cmaj.200484/tab-related-content).

Table 1 (part 1 of 2): Descriptive information on the study population of community-dwelling older adults, by country

\begin{tabular}{|c|c|c|c|c|c|c|c|}
\hline \multirow[b]{2}{*}{ Country } & \multirow[b]{2}{*}{$n$} & \multirow{2}{*}{$\begin{array}{c}\text { Age } \\
\text { Median (IQR) }\end{array}$} & \multirow{2}{*}{$\begin{array}{c}\text { Sex } \\
\text { Women, } \\
\%\end{array}$} & \multicolumn{2}{|c|}{ Socioeconomic* } & \multicolumn{2}{|c|}{ Lifestyle* } \\
\hline & & & & $\begin{array}{c}\text { Low education, } \\
\%\end{array}$ & $\begin{array}{c}\text { Low wealth, } \\
\%\end{array}$ & $\begin{array}{c}\text { Current smoker, } \\
\%\end{array}$ & $\begin{array}{c}\text { Alcohol } \\
\text { consumption: } \\
\text { never, \% }\end{array}$ \\
\hline Cuba & 2801 & 74 (11) & 65.3 & 57.9 & 27.9 & 19.4 & 87.5 \\
\hline Dominican Republic & 2009 & $74(11)$ & 66.0 & 89.6 & 35.0 & 12.4 & 82.2 \\
\hline Mexico & 2002 & $73(10)$ & 63.3 & 88.4 & 31.4 & 9.0 & 81.3 \\
\hline Peru & 1933 & $74(11)$ & 61.2 & 56.3 & 35.4 & 3.5 & 95.1 \\
\hline Puerto Rico & 2002 & $76(11)$ & 67.3 & 43.8 & 20.1 & 5.2 & 89.0 \\
\hline United States & 35747 & $57(17)$ & 55.6 & 27.2 & 20.3 & 21.4 & 52.3 \\
\hline Venezuela & 1958 & $71(10)$ & 63.7 & 81.3 & 32.0 & 11.5 & 76.5 \\
\hline China & 15924 & $62(14)$ & 51.2 & 72.6 & 24.6 & 28.9 & 70.7 \\
\hline Israel & 2545 & $64(15)$ & 55.1 & 24.0 & 21.4 & 15.4 & 71.1 \\
\hline Japan & 5144 & $63(12)$ & 50.9 & 29.6 & 25.2 & 22.1 & 44.2 \\
\hline South Korea & 8466 & $64(15)$ & 56.5 & 53.0 & 23.9 & 18.4 & 10.0 \\
\hline Austria & 4769 & $64(14)$ & 57.4 & 14.0 & 19.5 & 19.6 & 27.0 \\
\hline Belgium & 5413 & $61(17)$ & 54.1 & 21.2 & 19.6 & 19.3 & 19.6 \\
\hline Czech Republic & 12359 & $61(11)$ & 54.8 & 15.0 & 19.1 & 23.7 & 23.4 \\
\hline Denmark & 2982 & $60(16)$ & 53.4 & 14.1 & 16.4 & 29.1 & 8.0 \\
\hline Estonia & 5712 & $66(16)$ & 59.9 & 6.2 & 20.0 & 19.7 & 40.8 \\
\hline France & 5700 & $62(17)$ & 55.7 & 40.0 & 20.8 & 15.3 & 22.6 \\
\hline Germany & 2479 & $63(14)$ & 52.5 & 0.8 & 18.0 & 18.0 & 21.5 \\
\hline Greece & 4371 & $60(16)$ & 52.8 & 49.6 & 21.6 & 29.3 & 44.0 \\
\hline Italy & 3833 & $63(14)$ & 54.1 & 51.4 & 19.2 & 19.0 & 44.6 \\
\hline Netherlands & 3532 & $60(14)$ & 53.5 & 13.7 & 17.5 & 22.7 & 22.7 \\
\hline Poland & 10842 & $60(10)$ & 51.3 & 18.8 & 19.1 & 29.1 & 38.8 \\
\hline Slovenia & 1974 & $64(16)$ & 56.5 & 14.7 & 19.5 & 14.3 & 45.9 \\
\hline Spain & 10377 & $66(15)$ & 54.2 & 61.7 & 20.3 & 16.8 & 40.6 \\
\hline Sweden & 3220 & $64(15)$ & 53.3 & 35.0 & 20.0 & 17.1 & 18.4 \\
\hline Switzerland & 3367 & $63(16)$ & 53.4 & 10.8 & 18.0 & 19.5 & 14.1 \\
\hline UK & 15518 & $61(16)$ & 54.1 & 38.7 & 18.5 & 17.6 & 11.3 \\
\hline Australia & 2065 & $78(10)$ & 48.9 & 36.5 & 36.7 & 8.1 & 37.2 \\
\hline Missing & & - & - & 1.8 & 14.2 & 1.9 & 3.9 \\
\hline Total & 179044 & $63(16)$ & 55.0 & 36.3 & 21.6 & 20.7 & 41.6 \\
\hline
\end{tabular}


Table 1 (part 2 of 2): Descriptive information on the study population of community-dwelling older adults, by country

\begin{tabular}{|c|c|c|c|c|c|c|c|c|c|}
\hline \multirow[b]{2}{*}{ Country } & \multirow[b]{2}{*}{$n$} & \multirow{2}{*}{$\begin{array}{l}\text { Age } \\
\text { Median } \\
\text { (IQR) }\end{array}$} & \multirow{2}{*}{$\begin{array}{c}\text { Sex } \\
\text { Women, } \\
\%\end{array}$} & \multirow[b]{2}{*}{ CVD, $\%$} & \multicolumn{2}{|c|}{ Health } & \multirow[b]{2}{*}{$\begin{array}{c}\text { Depression, } \\
\%\end{array}$} & \multicolumn{2}{|c|}{ Social } \\
\hline & & & & & $\begin{array}{c}\text { Diabetes, } \\
\%\end{array}$ & $\begin{array}{c}\text { Hypertension, } \\
\%\end{array}$ & & $\begin{array}{c}\text { No } \\
\text { spouse, } \\
\%\end{array}$ & $\begin{array}{l}\text { Living } \\
\text { alone, } \\
\%\end{array}$ \\
\hline Cuba & 2801 & $74(11)$ & 65.3 & 35.2 & 18.6 & 51.5 & 16.8 & 57.3 & 8.7 \\
\hline Dominican Republic & 2009 & $74(11)$ & 66.0 & 18.6 & 14.1 & 61.8 & 26.9 & 70.6 & 12.6 \\
\hline Mexico & 2002 & $73(10)$ & 63.3 & 18.2 & 21.7 & 46.8 & 17.9 & 49.7 & 10.8 \\
\hline Peru & 1933 & $74(11)$ & 61.2 & 21.1 & 9.0 & 46.2 & 19.2 & 43.2 & 4.6 \\
\hline Puerto Rico & 2002 & $76(11)$ & 67.3 & 29.7 & 32.1 & 69.3 & 10.6 & 51.7 & 23.5 \\
\hline United States & 35747 & $57(17)$ & 55.6 & 18.4 & 12.5 & 39.8 & 16.0 & 29.5 & 17.5 \\
\hline Venezuela & 1958 & $71(10)$ & 63.7 & 25.5 & 16.2 & 62.5 & 19.7 & 52.2 & 3.1 \\
\hline China & 15924 & $62(14)$ & 51.2 & 16.6 & 7.0 & 29.1 & 33.7 & 17.8 & 11.5 \\
\hline Israel & 2545 & $64(15)$ & 55.1 & 21.8 & 21.8 & 44.0 & 35.9 & 21.2 & 14.3 \\
\hline Japan & 5144 & $63(12)$ & 50.9 & 15.6 & 12.1 & 36.2 & 17.4 & 20.4 & - \\
\hline South Korea & 8466 & $64(15)$ & 56.5 & 9.4 & 13.6 & 31.4 & 34.8 & 24.9 & 10.0 \\
\hline Austria & 4769 & $64(14)$ & 57.4 & 14.7 & 13.6 & 36.5 & 20.4 & 34.5 & 29.9 \\
\hline Belgium & 5413 & $61(17)$ & 54.1 & 15.4 & 10.1 & 31.7 & 28.0 & 27.9 & 22.4 \\
\hline Czech Republic & 12359 & $61(11)$ & 54.8 & 17.3 & 17.5 & 59.4 & 21.1 & 27.2 & 23.1 \\
\hline Denmark & 2982 & $60(16)$ & 53.4 & 13.0 & 8.4 & 29.6 & 17.5 & 29.2 & 23.6 \\
\hline Estonia & 5712 & $66(16)$ & 59.9 & 28.2 & 16.2 & 49.1 & 41.0 & 35.3 & 24.1 \\
\hline France & 5700 & $62(17)$ & 55.7 & 15.0 & 11.9 & 29.4 & 33.2 & 31.4 & 24.6 \\
\hline Germany & 2479 & $63(14)$ & 52.5 & 14.5 & 12.7 & 36.4 & 18.5 & 21.3 & 15.9 \\
\hline Greece & 4371 & $60(16)$ & 52.8 & 17.7 & 13.0 & 38.0 & 23.4 & 25.0 & 22.9 \\
\hline Italy & 3833 & $63(14)$ & 54.1 & 13.2 & 13.6 & 38.0 & 33.0 & 17.5 & 10.0 \\
\hline Netherlands & 3532 & $60(14)$ & 53.5 & 13.6 & 9.2 & 26.0 & 19.0 & 17.9 & 15.7 \\
\hline Poland & 10842 & $60(10)$ & 51.3 & 25.5 & 14.1 & 60.5 & 30.5 & 23.5 & 10.2 \\
\hline Slovenia & 1974 & $64(16)$ & 56.5 & 17.0 & 15.7 & 42.3 & 26.8 & 24.6 & 19.1 \\
\hline Spain & 10377 & $66(15)$ & 54.2 & 10.7 & 17.6 & 44.2 & 22.4 & 29.3 & 15.6 \\
\hline Sweden & 3220 & $64(15)$ & 53.3 & 18.7 & 9.4 & 30.0 & 18.9 & 21.9 & 20.5 \\
\hline Switzerland & 3367 & $63(16)$ & 53.4 & 9.6 & 7.9 & 28.7 & 18.2 & 25.0 & 21.3 \\
\hline UK & 15518 & $61(16)$ & 54.1 & 15.6 & 7.1 & 34.5 & 16.6 & 27.5 & 21.2 \\
\hline Australia & 2065 & $78(10)$ & 48.9 & 15.9 & 8.8 & 33.0 & 15.4 & 35.4 & 26.6 \\
\hline Missing & & - & - & 1.2 & 2.6 & 1.5 & 3.7 & 0.1 & 12.6 \\
\hline Total & 179044 & $63(16)$ & 55.0 & 17.4 & 12.7 & 40.4 & 23.4 & 28.3 & 17.5 \\
\hline
\end{tabular}

Note: $\mathrm{CVD}=$ cardiovascular disease, $\mathrm{IQR}=$ interquartile range.

${ }^{*}$ Categories of socioeconomic and lifestyle factors: Education: low (up to primary education), middle (secondary) and high levels (tertiary); Wealth: first (low) to fifth quintile (high); Smoking: current, ever, never; Alcohol consumption: never, rare (once or less a week) and often (twice or more per week).

\section{Outcomes and variables}

We obtained all data from the ATHLOS harmonized data set, which provides comparable measures across cohort studies. The primary outcome was mortality. Information on date of death was collected using death registers (ALSA, COURAGE, ELSA, HAPIEE, Seniors-ENRICA, HRS, JSTAR, KLOSA, SHARE) or interviews with participants' family or informants (the 10/66 study, CHARLS, ATTICA). The censoring time was set to be the end of follow-up in each cohort study. The longest follow-up period was 20 years in ALSA and HRS, and the shortest was 2 years in CHARLS.
Other variables of interest included socioeconomic (education, wealth), lifestyle (smoking, alcohol consumption), health (cardiovascular disease, diabetes, hypertension, depression) and social factors (living alone, no spouse or partner) at baseline. These variables were selected as most cohorts had available data. We categorized education into low (up to primary education), middle (secondary) and high (tertiary) levels. Wealth was based on individual or household income and other financial information (such as pensions, insurance) and was divided into quintiles within specific cohorts. Self-reported smoking status included 3 groups: nonsmoker, ex-smoker and current smoker. Alcohol consumption was based on self-reported frequency 
and categorized into 3 groups: never, rare ( $\leq 1$ time/wk) and often ( $\geq 2$ times/wk). Four types of health conditions (cardiovascular disease, diabetes, hypertension and depression) were recorded as binary variables (yes or no). We used self-reported diagnosis of cardiovascular disease (any of angina, stroke, myocardial infarction, heart attack, coronary heart disease, congestive heart failure, heart murmur, valve disease and cerebral vascular disease), diabetes and hypertension to identify patients with these conditions. We determined depression status using the available assessment tools and their established cut-offs in specific cohort studies. We dichotomized (yes or no) 2 social factors, living alone and no spouse or partner, based on self-reported information. The Japanese cohort (JSTAR) did not have data on living alone; therefore, analyses related to this variable included only 27 countries.

To establish baseline conditions of these factors, we obtained all variables from the first wave if available. If some variables were not available at the baseline, we used information from the second or third follow-up waves to inform possible conditions of participants. More details on data harmonization are available online at https:/github.com/athlosproject/athlos-project.github.io.

To contextualize the results, we obtained the gender inequality index and the gender development index for each country from the
United Nations (UN) Human Development Reports 2018. ${ }^{25}$ The gender inequality index focuses on the disadvantages that women face in terms of reproductive health, empowerment and labour market. ${ }^{26}$ The gender development index was developed to measure disparities of human development achievements between men and women, including health, knowledge and standard of living. ${ }^{26}$

\section{Statistical analysis}

A factor might lead to sex differences in mortality in 2 ways. First, if a factor has similar effects on females and males, the variation could be a result of differential prevalence of this factor across the sexes. Higher mortality in males could be (largely or partially) attributed to higher prevalence of this factor. Adjusting for this factor as a covariate should attenuate the effect size of sex. Second, if a factor has different effects on females and males, sex differences might not be attenuated by the prevalence of this factor. In this case, the model should include the interaction terms between sex and this factor to account for its effect. To estimate hazard ratios of mortality between men and women, we carried out Cox proportion hazards modelling to include different factors as covariates (Model $a$ ) or their interaction terms with sex (Model $b$ ). We fitted each factor individually in Model $a$ or Model $b$

\begin{tabular}{lc} 
Country & HR (95\% CI) \\
\hline Mexico & $1.07(0.81-1.40)$ \\
Denmark & $1.28(1.04-1.57)$ \\
Austria & $1.29(1.02-1.64)$ \\
Sweden & $1.32(1.10-1.57)$ \\
China & $1.34(1.17-1.53)$ \\
Puerto Rico & $1.35(1.07-1.70)$ \\
US & $1.43(1.38-1.48)$ \\
Germany & $1.43(1.07-1.92)$ \\
Cuba & $1.46(1.24-1.72)$ \\
Israel & $1.46(1.17-1.81)$ \\
UK & $1.46(1.35-1.57)$ \\
Australia & $1.48(1.35-1.63)$ \\
Italy & $1.56(1.27-1.91)$ \\
Dominican Republic & $1.59(1.32-1.91)$ \\
Spain & $1.66(1.45-1.90)$ \\
France & $1.77(1.44-2.16)$ \\
Peru & $1.77(1.29-2.44)$ \\
Venezuela & $1.82(1.37-2.41)$ \\
Belgium & $1.83(1.48-2.25)$ \\
Czech Republic & $1.83(1.53-2.18)$ \\
Netherlands & $1.84(1.44-2.35)$ \\
Greece & $1.90(1.46-2.46)$ \\
South Korea & $1.92(1.67-2.21)$ \\
Poland & $2.05(1.74-2.42)$ \\
Switzerland & $2.13(1.51-3.01)$ \\
Estonia & $2.29(1.83-2.86)$ \\
Slovenia & $2.33(1.32-4.09)$ \\
Japan & $2.44(1.54-3.85)$ \\
Overall $\left.~^{2}=71.5 \%, p<0.001\right)$ & $1.60(1.51-1.70)$ \\
&
\end{tabular}

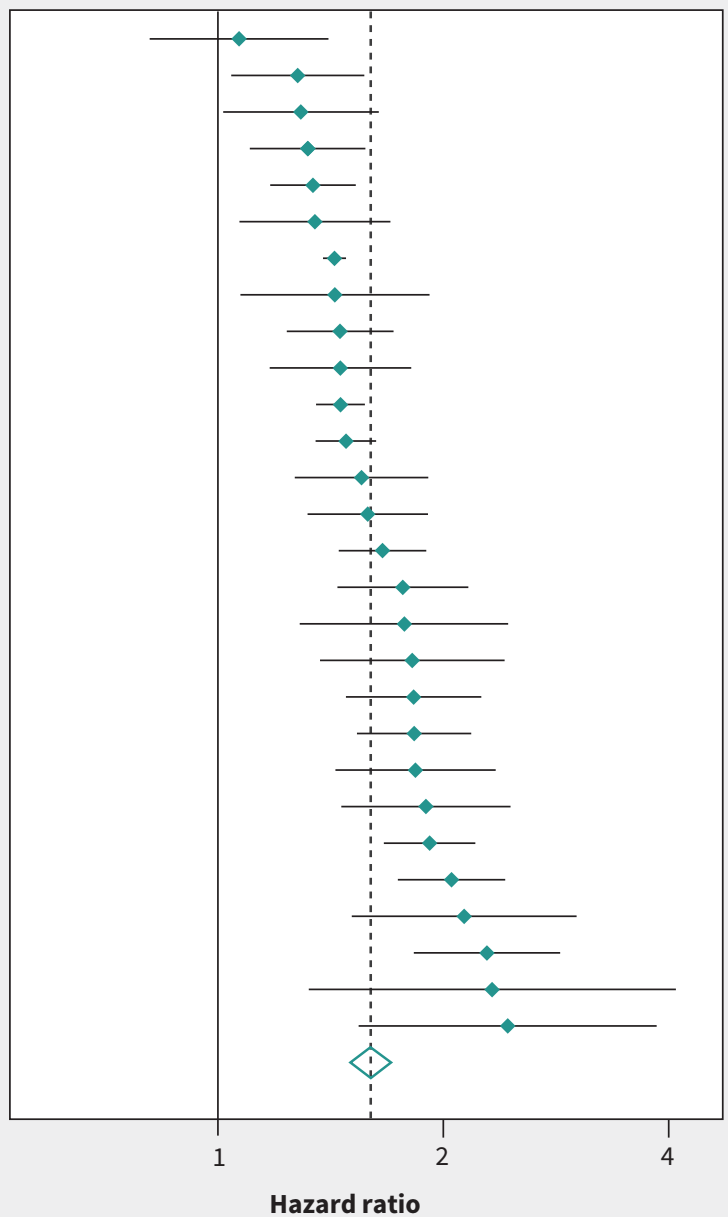

Figure 1: Age-adjusted hazard ratios of mortality between men and women (reference). Note: $\mathrm{Cl}=$ confidence interval, $\mathrm{HR}=$ hazard ratio. 
to investigate changes in the sex coefficient compared with the original model, which included only sex and age. We included factors that were identified to attenuate age-adjusted hazard ratios between men and women in 1 multivariable model. We estimated the marginal effects of sex on mortality for Model $a$ and $b$ with adjustment for age and calculated the percentage of change in estimates. According to the literature, a 10\% change between unadjusted and adjusted estimates is generally used in confounder selection. ${ }^{27}$ Given that multiple factors could be related to sex differences in mortality, we used $a>5 \%$ attenuation to indicate partial contribution of a factor.

We used a 2-stage individual participant-data analytical approach ${ }^{28}$ to generate country-specific and overall pooled estimates. Given the large heterogeneity, we used a random-effects meta-analysis model to identify the distribution of sex differences in mortality across countries. We used Spearman rank correlation to estimate the direction and strength of monotonic relationships between adjusted hazard ratios and the gender inequality and gender development indicators individually.

We examined the proportional hazards assumption using the Schoenfeld residual test and interaction terms between time and covariates. Because the effect sizes were generally small, modelling did not further include variables with time-varying effects (Appendix 1, Table S2). We carried out full models including all socioeconomic, lifestyle, health and social factors (with or without living alone) as sensitivity analyses (Appendix 1, Table S3). To address time-varying covariates, we performed additional sensitivity analyses to incorporate lifestyle, health and social factors at different waves in modelling (Appendix 1, Table S4). To test the impact of birth cohorts, sensitivity analyses further included birth cohorts and their interaction terms with age in the modelling (Appendix 1, Table S5). We carried out all analyses using Stata 15.0.

\section{Ethics approval}

The project was approved by the research ethics committee at Fundación Sant Joan de Déu, Barcelona, Spain (code 635316-2).

\section{Results}

We included 179044 participants in the analysis. The median age of participants was 63 years, with an interquartile range (IQR) between 55 and 71 years (Table 1$)$. Nearly 55\% were women $(n=98430)$. The median period of follow-up was 4 years (IQR $5 \mathrm{yr}$ ), and $14.7 \%$ ( $n=$ 26484 ) died at the end of follow-up. Among the participants, $36.3 \%$ had primary education or less, $20.7 \%$ were current smokers and just more than $40 \%$ abstained from alcohol. Among the 4 health conditions, hypertension (40.4\%) was the most frequent and the least frequent was diabetes $(12.7 \%)$. There were $28.3 \%$ participants without a spouse and $17.5 \%$ lived alone. More detailed results, stratified by sex, are reported in Appendix 1, Table S6.

Based on the pooled estimate, men had a 60\% higher mortality risk than women (1.60; 95\% confidence interval [Cl] 1.51-1.70). The heterogeneity $\left(R^{2}\right)$ across countries was $71.5 \%$, with a range from 1.07 (95\% Cl 0.81-1.41) in Mexico to 2.44 (95\% Cl 1.54-3.85) in Japan (Figure 1). The strength of association between sex and mortality did not decrease when we adjusted for most socioeconomic, lifestyle, social or health factors (Table 2). Sex differences in mortality became wider when we accounted for education, wealth, alcohol consumption, depression and no spouse. Only adjustment for smoking $(1.47 ; 95 \% \mathrm{Cl}$ $1.39-1.55)$ and cardiovascular disease $(1.56 ; 95 \% \mathrm{Cl} 1.46-1.66)$ slightly attenuated sex differences in mortality. Country-specific estimates are reported in Appendix 1, Table S7. The amount of reduction was similar across Model $a$ and Model $b$ (Appendix 1, Table S8). Only a small number of interaction terms with sex achieved statistical significance.

Because most attenuations were found in smoking and cardiovascular disease (Appendix 1, Table S8), we stratified age-adjusted hazard ratios by smoking (Table 3 ), and by smoking and cardiovascular disease (Table 4). The overall sex differences reduced in nonsmokers $(1.40 ; 95 \% \mathrm{Cl} 1.32-1.49)$ and ex-smokers $(1.43 ; 95 \% \mathrm{Cl}$ 1.32-1.56). Adjustment for smoking and cardiovascular disease further attenuated the hazard ratio slightly $(1.44 ; 95 \% \mathrm{Cl} 1.36-$ 1.52). When stratified by smoking status and cardiovascular disease, the overall sex differences decreased to 1.34 (95\% Cl 1.251.44) in nonsmokers who did not have cardiovascular disease.

We observed no clear patterns in the scatter plots between the adjusted hazard ratios and the $2 \mathrm{UN}$ indicators at the country level (Figure 2). Spearman correlation coefficients were $0.05(p=0.8)$ for the gender inequality index (Figure $2 A)$ and $0.12(p=0.5)$ for the gender development index (Figure 2B). The full models including all factors did not attenuate sex differences in mortality (Appendix 1, Table S3). The sensitivity analyses incorporating time-varying covariates across follow-up waves showed results similar to those of the main analysis (Appendix 1, Table S4). Because birth cohorts had limited effects on the results (Appendix 1, Table S5), the main analyses did not include the birth cohort variable.

Table 2: Pooled estimates for age-adjusted hazard ratios of mortality between men and women (reference) adjusted for socioeconomic, lifestyle, health and social factors

\begin{tabular}{|lccc|}
\hline Variable & \multicolumn{1}{c}{$\begin{array}{c}\text { Pooled HR } \\
(95 \% \text { Cl) }\end{array}$} & $\boldsymbol{I}^{2}, \%$ & Change, \%* \\
\hline Age & $1.60(1.51-1.70)$ & 71.5 & - \\
\hline $\begin{array}{l}\text { Socioeconomic } \\
\text { Education }\end{array}$ & $1.68(1.58-1.80)$ & 76.1 & 10.4 \\
\hline Wealth & $1.64(1.56-1.73)$ & 52.5 & 5.3 \\
\hline Lifestyle & & & \\
\hline Smoking & $1.47(1.39-1.55)$ & 57.6 & -18.0 \\
\hline Alcohol consumption & $1.74(1.62-1.88)$ & 79.3 & 17.8 \\
\hline Health & & & \\
\hline Cardiovascular disease & $1.56(1.46-1.66)$ & 73.6 & -5.4 \\
\hline Diabetes & $1.58(1.49-1.68)$ & 67.0 & -2.7 \\
\hline Hypertension & $1.61(1.52-1.70)$ & 69.1 & 1.3 \\
\hline Depression & $1.72(1.61-1.85)$ & 77.7 & 15.4 \\
\hline Social & & & \\
\hline No spouse & $1.71(1.60-1.82)$ & 72.2 & 14.1 \\
\hline Living alone & $1.57(1.49-1.65)$ & 53.1 & -4.0 \\
\hline
\end{tabular}

Note: $\mathrm{Cl}=$ confidence interval, $\mathrm{HR}=$ hazard ratio.

${ }^{*}$ Change, \%: the percentage change in effect size compared with the age-adjusted HR on the logarithmic scale. 
Table 3: Age-adjusted hazard ratios of mortality between men and women (reference), adjusted for smoking

\begin{tabular}{|c|c|c|c|c|c|c|c|}
\hline \multirow[b]{2}{*}{ Country } & \multirow[b]{2}{*}{$\begin{array}{c}\text { Model 1: } \\
\text { adjusted } \\
\text { for age }\end{array}$} & \multicolumn{2}{|c|}{$\begin{array}{l}\text { Model 2a: adjusted for age, } \\
\text { smoking }\end{array}$} & \multicolumn{4}{|c|}{$\begin{array}{c}\text { Model } 2 b \text { : adjusted for age, interaction between } \\
\text { sex and smoking status }\end{array}$} \\
\hline & & & $\begin{array}{l}\text { Change, } \\
\%^{*}\end{array}$ & Nonsmoker & Ex-smoker & $\begin{array}{l}\text { Current } \\
\text { smoker }\end{array}$ & $\begin{array}{c}\text { Change, } \\
\%^{*}\end{array}$ \\
\hline Cuba & $1.5(1.2-1.7)$ & $1.3(1.1-1.6)$ & -24.2 & $1.4(1.1-1.9)$ & $1.1(0.8-1.6)$ & $1.5(1.0-2.1)$ & -22.3 \\
\hline Dominican Republic & $1.6(1.3-1.9)$ & $1.5(1.3-1.9)$ & -6.0 & $1.3(1.0-1.8)$ & $1.9(1.4-2.6)$ & $1.3(0.8-2.1)$ & -10.4 \\
\hline Mexico & $1.1(0.8-1.4)$ & $1.1(0.7-1.5)$ & -19.6 & $1.3(0.9-2.0)$ & $0.6(0.3-1.0)$ & $0.9(0.2-4.2)$ & -17.7 \\
\hline Peru & $1.8(1.3-2.4)$ & $1.7(1.2-2.4)$ & -6.7 & $1.7(1.2-2.5)$ & $1.4(0.5-3.7)$ & $1.8(0.2-16.0)$ & -7.6 \\
\hline Puerto Rico & $1.4(1.1-1.7)$ & $1.2(0.9-1.5)$ & -46.7 & $1.3(1.0-1.8)$ & $1.0(0.6-1.6)$ & $0.9(0.4-2.0)$ & -34.9 \\
\hline United States & $1.4(1.4-1.5)$ & $1.3(1.3-1.4)$ & -24.9 & $1.2(1.2-1.3)$ & $1.3(1.2-1.4)$ & $1.4(1.3-1.5)$ & -27.3 \\
\hline Venezuela & $1.8(1.4-2.4)$ & $1.9(1.4-2.5)$ & 3.0 & $2.0(1.3-3.1)$ & $1.5(0.9-2.5)$ & $2.3(0.9-5.8)$ & 5.5 \\
\hline China & $1.3(1.2-1.5)$ & $1.2(1.0-1.4)$ & -42.0 & $1.2(1.0-1.4)$ & $1.3(0.8-2.3)$ & $1.1(0.8-1.5)$ & -43.8 \\
\hline Israel & $1.5(1.2-1.8)$ & $1.5(1.2-1.8)$ & -0.8 & $1.3(1.0-1.8)$ & $1.2(0.7-1.8)$ & $3.4(1.7-6.8)$ & 1.5 \\
\hline Japan & $2.4(1.5-3.9)$ & $1.8(1.0-3.2)$ & -33.5 & $2.4(1.1-4.9)$ & $0.7(0.3-1.8)$ & $2.9(0.7-12.1)$ & -33.1 \\
\hline South Korea & $1.9(1.7-2.2)$ & $1.7(1.4-2.0)$ & -22.7 & $1.7(1.4-2.1)$ & $2.4(1.0-5.9)$ & $1.2(0.8-1.8)$ & -20.7 \\
\hline Austria & $1.3(1.0-1.6)$ & $1.3(1.0-1.7)$ & -1.4 & $1.3(1.0-1.8)$ & $1.3(0.7-2.4)$ & $1.1(0.6-2.0)$ & -4.2 \\
\hline Belgium & $1.8(1.5-2.2)$ & $1.7(1.3-2.1)$ & -15.5 & $1.7(1.2-2.4)$ & $1.8(1.1-3.0)$ & $1.5(0.9-2.5)$ & -14.1 \\
\hline Czech Republic & $1.8(1.5-2.2)$ & $1.7(1.4-2.0)$ & -14.6 & $1.4(1.1-1.8)$ & $2.0(1.3-3.1)$ & $2.3(1.5-3.5)$ & -8.8 \\
\hline Denmark & $1.3(1.0-1.6)$ & $1.2(1.0-1.5)$ & -16.0 & $1.2(0.8-1.8)$ & $1.3(0.9-1.9)$ & $1.2(0.8-1.6)$ & -14.5 \\
\hline Estonia & $2.3(1.8-2.9)$ & $1.6(1.3-2.1)$ & -40.5 & $1.3(0.9-1.9)$ & $1.7(1.0-2.8)$ & $2.8(1.4-5.7)$ & -41.7 \\
\hline France & $1.8(1.4-2.2)$ & $1.6(1.2-2.0)$ & -14.4 & $1.5(1.1-2.0)$ & $1.9(1.2-3.0)$ & $2.0(1.0-3.8)$ & -11.7 \\
\hline Germany & $1.4(1.1-1.9)$ & $1.3(0.9-1.8)$ & -29.6 & $1.3(0.8-1.9)$ & $1.3(0.6-2.5)$ & $1.4(0.7-2.8)$ & -31.0 \\
\hline Greece & $1.9(1.5-2.5)$ & $1.8(1.3-2.4)$ & -11.1 & $1.5(1.1-2.1)$ & $1.9(0.8-4.8)$ & $4.2(1.6-10.8)$ & 16.8 \\
\hline Italy & $1.6(1.3-1.9)$ & $1.4(1.1-1.7)$ & -27.1 & $1.2(0.9-1.6)$ & $1.4(0.9-2.3)$ & $2.4(1.3-4.3)$ & -23.1 \\
\hline Netherlands & $1.8(1.4-2.3)$ & $1.9(1.4-2.4)$ & 1.2 & $2.3(1.5-3.5)$ & $1.7(1.0-2.7)$ & $1.5(0.9-2.6)$ & 1.1 \\
\hline Poland & $2.1(1.7-2.4)$ & $1.7(1.4-2.0)$ & -27.2 & $1.1(0.8-1.5)$ & $2.1(1.5-3.0)$ & $2.2(1.6-3.0)$ & -32.0 \\
\hline Slovenia & $2.3(1.3-4.1)$ & $2.0(1.1-3.7)$ & -17.9 & $2.0(1.0-4.2)$ & $1.1(0.3-4.2)$ & $4.7(0.6-38.4)$ & -17.3 \\
\hline Spain & $1.7(1.5-1.9)$ & $1.7(1.4-2.0)$ & 0.4 & $1.5(1.3-1.9)$ & $2.1(1.3-3.4)$ & $2.2(1.1-4.2)$ & 13.1 \\
\hline Sweden & $1.3(1.1-1.6)$ & $1.3(1.0-1.5)$ & -18.0 & $1.1(0.9-1.5)$ & $1.2(0.9-1.7)$ & $1.8(1.1-2.8)$ & -16.9 \\
\hline Switzerland & $2.1(1.5-3.0)$ & $2.2(1.5-3.2)$ & 4.2 & $2.1(1.3-3.5)$ & $1.9(0.8-4.4)$ & $2.9(1.2-6.7)$ & 2.4 \\
\hline United Kingdom & $1.5(1.4-1.6)$ & $1.4(1.3-1.5)$ & -6.3 & $1.5(1.3-1.7)$ & $1.4(1.2-1.5)$ & $1.5(1.3-1.8)$ & -4.9 \\
\hline Australia & $1.5(1.4-1.6)$ & $1.4(1.2-1.5)$ & -17.0 & $1.4(1.2-1.6)$ & $1.5(1.2-1.7)$ & $1.3(0.9-1.8)$ & -15.7 \\
\hline Pooled estimate & $1.6(1.5-1.7)$ & $1.5(1.4-1.5)$ & & $1.4(1.3-1.5)$ & $1.4(1.3-1.6)$ & $1.6(1.4-1.8)$ & \\
\hline $1^{2}$ & 71.5 & 57.6 & & 35.7 & 33.2 & 43.8 & \\
\hline
\end{tabular}

\section{Interpretation}

The analysis of a harmonized data set of 12 population-based cohort studies shows that men had a $60 \%$ higher mortality risk than women, but this gap varied across countries. Among a wide range of socioeconomic status, lifestyle, health and social factors, only smoking and cardiovascular disease attenuated sex differences in mortality by up to $22 \%$.

The results of this study correspond to the literature on life expectancy and mortality rates ${ }^{4,5}$ and highlight sex differences in mortality at older age and substantial heterogeneity across countries. Although the ATHLOS harmonized data set and existing studies mainly used the measure for biological sex, the effects of sex on mortality should include not only physiologic variation between men and women but also the social construct of gender, which differs across societies. In particular, the large variation across countries may imply a greater effect of gender than sex. Although the biology of the sexes is consistent across populations, variation in cultural, societal and historical contexts can lead to different life experiences of men and women and variation in the mortality gap across countries. ${ }^{6}$

Among all factors, smoking had the largest contribution to the difference in mortality between men and women, particularly in the countries where men had more than twice the mortality risk of women (Estonia, Poland and Japan). International studies and primary research in these regions have reported large sex 
Table 4: Age-adjusted hazard ratios of mortality between men and women (reference), adjusting for smoking and cardiovascular disease

\begin{tabular}{|c|c|c|c|c|c|c|}
\hline \multirow[b]{2}{*}{ Country } & \multirow{2}{*}{$\begin{array}{l}\text { Model 1: } \\
\text { adjusted } \\
\text { for age }\end{array}$} & \multirow{2}{*}{$\begin{array}{c}\text { Model } a \text { : adjusted } \\
\text { for age, smoking, } \\
\text { CVD }\end{array}$} & \multicolumn{4}{|c|}{ Model $b$ : adjusted for age, interaction between sex, smoking and CVD } \\
\hline & & & $\begin{array}{c}\text { No CVD, never } \\
\text { smoker }\end{array}$ & $\begin{array}{l}\text { No CVD, ever } \\
\text { smoker }\end{array}$ & $\begin{array}{l}\text { CVD, never } \\
\text { smoker }\end{array}$ & $\begin{array}{l}\text { CVD, ever } \\
\text { smoker }\end{array}$ \\
\hline Cuba & $1.5(1.2-1.7)$ & $1.3(1.1-1.6)$ & $1.5(1.0-2.1)$ & $1.5(1.1-2.2)$ & $1.4(0.9-2.1)$ & $1.0(0.7-1.4)$ \\
\hline Dominican Republic & $1.6(1.3-1.9)$ & $1.6(1.3-1.9)$ & $1.3(0.9-1.8)$ & $1.7(1.2-2.2)$ & $1.7(0.9-3.0)$ & $1.9(1.1-3.2)$ \\
\hline Mexico & $1.1(0.8-1.4)$ & $1.0(0.7-1.5)$ & $1.3(0.8-2.0)$ & $0.7(0.4-1.5)$ & $1.2(0.5-2.8)$ & $0.2(0.1-0.7)$ \\
\hline Peru & $1.8(1.3-2.4)$ & $1.8(1.3-2.5)$ & $1.8(1.2-2.8)$ & $1.7(0.5-5.8)$ & $2.1(1.1-4.0)$ & $1.3(0.3-4.7)$ \\
\hline Puerto Rico & $1.4(1.1-1.7)$ & $1.2(0.9-1.5)$ & $1.4(0.9-2.1)$ & $0.8(0.5-1.4)$ & $1.3(0.8-2.1)$ & $1.1(0.6-2.1)$ \\
\hline United States & $1.4(1.4-1.5)$ & $1.3(1.2-1.3)$ & $1.2(1.1-1.3)$ & $1.3(1.2-1.4)$ & $1.2(1.0-1.3)$ & $1.1(1.0-1.2)$ \\
\hline Venezuela & $1.8(1.4-2.4)$ & $1.9(1.4-2.6)$ & $1.8(1.1-3.0)$ & $1.1(0.6-2.0)$ & $3.7(1.7-8.4)$ & $2.6(1.3-5.2)$ \\
\hline China & $1.3(1.2-1.5)$ & $1.2(1.0-1.4)$ & $1.1(0.9-1.3)$ & $1.3(0.9-1.8)$ & $1.5(1.1-2.1)$ & $0.9(0.6-1.5)$ \\
\hline Israel & $1.5(1.2-1.8)$ & $1.3(1.1-1.7)$ & $1.3(0.9-1.9)$ & $1.7(1.1-2.8)$ & $1.1(0.7-1.8)$ & $1.1(0.6-1.9)$ \\
\hline Japan & $2.4(1.5-3.9)$ & $2.0(1.1-3.6)$ & $3.0(1.2-7.6)$ & $2.1(0.6-6.8)$ & $1.8(0.5-6.3)$ & $0.6(0.2-2.2)$ \\
\hline South Korea & $1.9(1.7-2.2)$ & $1.6(1.4-1.9)$ & $1.6(1.3-1.9)$ & $1.4(0.9-2.0)$ & $2.0(1.4-3.0)$ & $1.5(0.6-3.8)$ \\
\hline Austria & $1.3(1.0-1.6)$ & $1.2(1.0-1.6)$ & $1.4(1.0-2.0)$ & $1.0(0.6-1.7)$ & $1.2(0.6-2.3)$ & $0.9(0.4-1.9)$ \\
\hline Belgium & $1.8(1.5-2.2)$ & $1.6(1.3-2.1)$ & $1.3(0.9-2.1)$ & $1.3(0.9-2.1)$ & $2.1(1.2-3.9)$ & $1.9(1.0-3.5)$ \\
\hline Czech Republic & $1.8(1.5-2.2)$ & $1.6(1.3-1.9)$ & $1.3(0.9-1.8)$ & $2.0(1.4-2.9)$ & $1.4(1.0-2.1)$ & $2.0(1.1-3.7)$ \\
\hline Denmark & $1.3(1.0-1.6)$ & $1.2(1.0-1.5)$ & $0.9(0.6-1.5)$ & $1.0(0.8-1.4)$ & $2.4(1.1-5.2)$ & $1.5(1.0-2.4)$ \\
\hline Estonia & $2.3(1.8-2.9)$ & $1.6(1.2-2.1)$ & $1.3(0.7-2.3)$ & $2.1(1.2-3.5)$ & $1.2(0.7-2.2)$ & $2.0(1.0-3.7)$ \\
\hline France & $1.8(1.4-2.2)$ & $1.5(1.2-2.0)$ & $1.1(0.7-1.6)$ & $1.9(1.2-2.9)$ & $2.0(1.3-3.2)$ & $1.5(0.8-3.1)$ \\
\hline Germany & $1.4(1.1-1.9)$ & $1.3(0.9-1.7)$ & $1.1(0.7-1.9)$ & $1.1(0.6-1.9)$ & $1.2(0.6-2.4)$ & $1.5(0.6-4.0)$ \\
\hline Greece & $1.9(1.5-2.5)$ & $1.7(1.2-2.3)$ & $2.0(1.3-3.1)$ & $2.9(1.2-6.8)$ & $0.9(0.5-1.6)$ & $2.8(0.9-9.1)$ \\
\hline Italy & $1.6(1.3-1.9)$ & $1.3(1.1-1.7)$ & $1.4(1.0-2.0)$ & $1.6(1.0-2.5)$ & $0.5(0.2-1.0)$ & $1.6(0.8-3.1)$ \\
\hline Netherlands & $1.8(1.4-2.3)$ & $1.8(1.4-2.4)$ & $2.3(1.4-3.7)$ & $1.3(0.9-1.9)$ & $2.1(0.9-4.7)$ & $1.9(0.9-4.0)$ \\
\hline Poland & $2.1(1.7-2.4)$ & $1.7(1.4-2.0)$ & $1.0(0.7-1.4)$ & $2.0(1.5-2.7)$ & $1.3(0.8-2.3)$ & $2.2(1.4-3.4)$ \\
\hline Slovenia & $2.3(1.3-4.1)$ & $2.0(1.1-3.6)$ & $1.9(0.8-4.7)$ & $3.3(0.8-14.6)$ & $2.1(0.6-7.1)$ & $0.4(0.1-2.3)$ \\
\hline Spain & $1.7(1.5-1.9)$ & $1.7(1.4-2.0)$ & $1.4(1.1-1.8)$ & $2.3(1.4-3.6)$ & $2.2(1.4-3.3)$ & $1.5(0.7-3.2)$ \\
\hline Sweden & $1.3(1.1-1.6)$ & $1.2(1.0-1.4)$ & $1.2(0.9-1.8)$ & $1.3(0.9-1.7)$ & $0.9(0.6-1.4)$ & $1.0(0.6-1.7)$ \\
\hline Switzerland & $2.1(1.5-3.0)$ & $2.2(1.5-3.2)$ & $2.0(1.2-3.5)$ & $1.7(0.9-3.2)$ & $2.1(0.6-7.4)$ & $6.4(0.9-48.5)$ \\
\hline United Kingdom & $1.5(1.4-1.6)$ & $1.4(1.3-1.5)$ & $1.4(1.2-1.7)$ & $1.3(1.2-1.5)$ & $1.4(1.0-1.8)$ & $1.3(1.1-1.5)$ \\
\hline Australia & $1.5(1.4-1.6)$ & $1.3(1.2-1.5)$ & $1.3(1.1-1.5)$ & $1.3(1.1-1.6)$ & $1.5(1.1-2.1)$ & $1.1(0.7-1.7)$ \\
\hline Pooled estimate & $1.6(1.5-1.7)$ & $1.4(1.4-1.5)$ & $1.3(1.3-1.4)$ & $1.4(1.3-1.5)$ & $1.4(1.3-1.6)$ & $1.3(1.2-1.5)$ \\
\hline R & 71.5 & 62.4 & 26.7 & 41.2 & 42.8 & 44.4 \\
\hline
\end{tabular}

differences in the prevalence of smoking and related morbidity and mortality, with trends that are stable or decreasing in men but increasing in women. ${ }^{29-33}$ Although tobacco control polices have been suggested to reduce smoking-related mortality in some Eastern European countries, ${ }^{32,34}$ their effects may differ between men and women. We observed differential impacts of smoking and cardiovascular disease on mortality in men and women across countries. This might indicate that male smokers experienced different risk factors or prognosis of chronic conditions than their female counterparts. ${ }^{35}$

The heterogeneity of sex differences in mortality across countries may indicate the substantial impact of gender on healthy aging in addition to biological sex, and the crucial contributions of smoking may also vary across different populations. Public health policies must recognize variation among genders and further incorporate cultural and societal factors within and across countries. ${ }^{36}$ For example, given that opposite trends in prevalence of smoking, associated morbidity and mortality have been observed in men (decreasing) and women (increasing), $32,33,37$ tobacco control policy-makers should consider changes in gender roles over time and the variation in life experiences across different societies so as to reduce the impact of smoking on the whole population. To strengthen evidence and inform populationlevel interventions, advanced epidemiologic methods for causal inference are needed to facilitate subgroup and mediation analyses in future research. ${ }^{38}$ 
A)

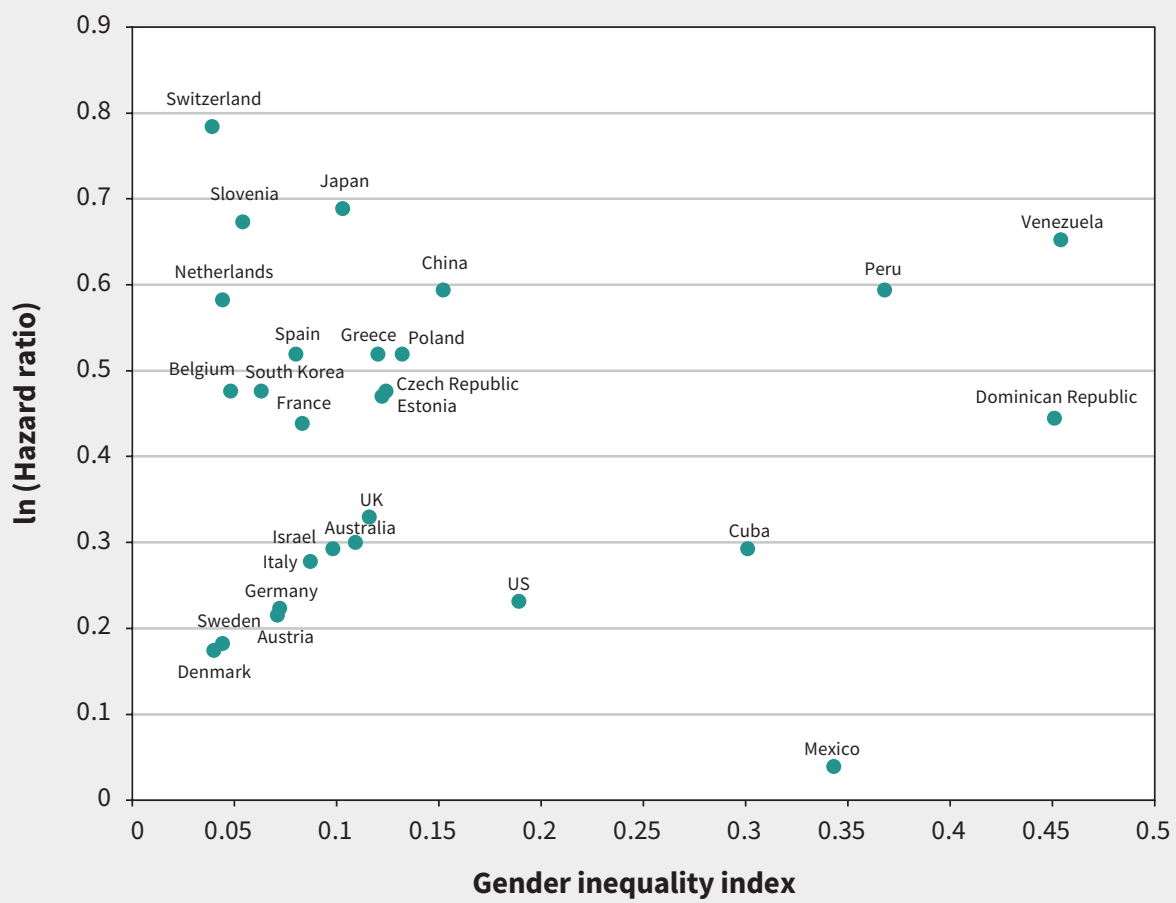

B)

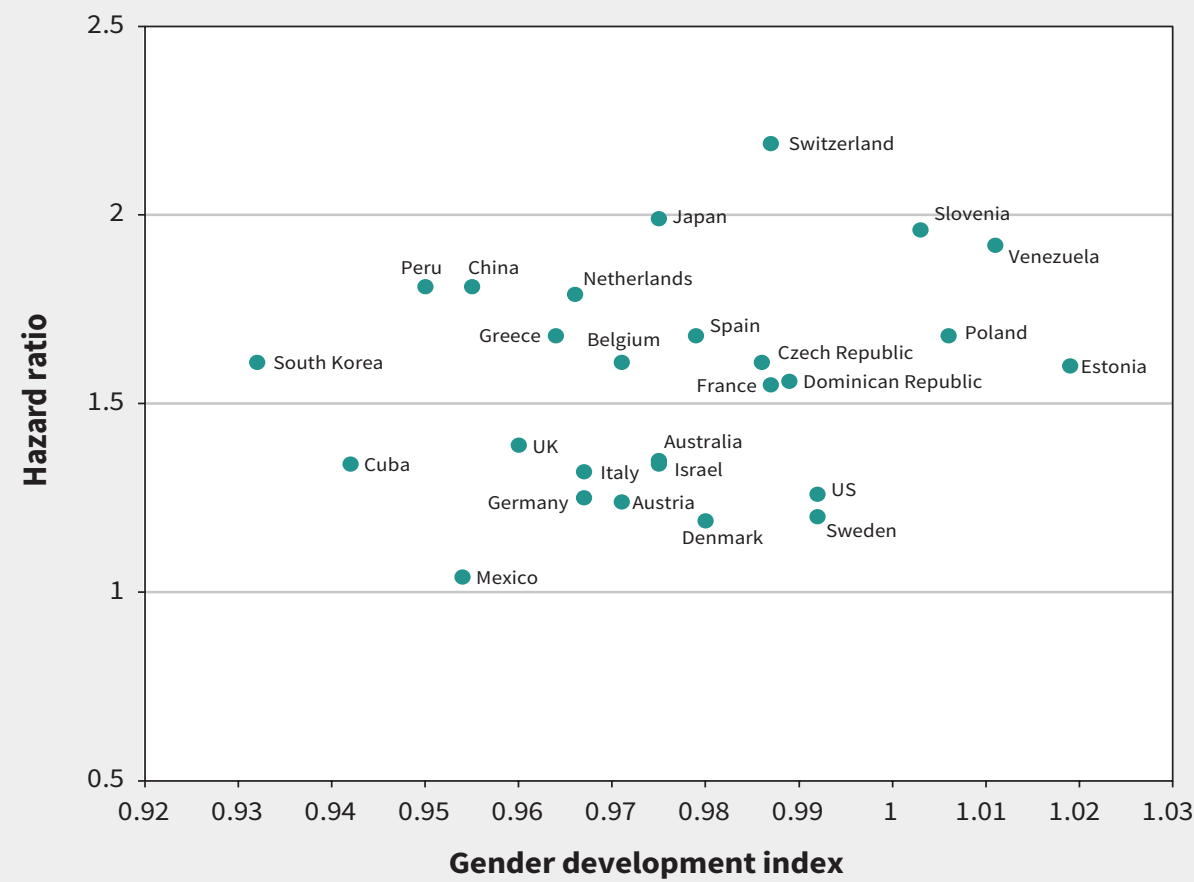

Figure 2: Scatter plots of country-specific hazard ratios for men versus women, adjusted for age, smoking and cardiovascular disease, according to the United Nations' (A) gender inequality index and (B) gender development index across countries. Gender inequality index: Higher values indicate more gender inequality. Gender development index: 1 indicates good equality of development between women and men. Values $<1$ and $>1$ suggest less equality of development between women and men.

\section{Limitations}

Variation in study designs across cohort studies - such as sampling methods, response rates and the length of follow-up periods - might affect representation of older populations in specific countries. In addition, most cohort studies were from high-income countries. This might limit generalizability of the findings. Although all variables were harmonized, methods of data collection - such as mortality data based on family-reported death or national death registry - could 
still differ across cohort studies, and this may lead to misclassification and variation in measurements. The residual sex differences might be attributed to other factors such as physical activity, but several cohort studies did not have comparable data for harmonization. Data on wealth based on individual or household income could be inaccurate for older participants who were retired. Some cohort studies had more comprehensive data on pension, insurance or other financial information, and we used these to generate the relative wealth quintile where possible. Some lifestyle, health and social factors were likely to change over time, but the results of models incorporating time-varying covariates were similar to the main analysis. Although we obtained the UN gender inequality and development indexes to contextualize the results, these 2 indexes composite several health (life-expectancy) and socioeconomic indicators (education, employment and living standards) and might not sufficiently reflect societal and cultural factors across countries. The change-in-estimate approach might be limited to address potential confounders on different pathways between sex, risk factors and mortality. ${ }^{38}$ However, complex modelling frameworks can be difficult to incorporate into the 2-stage individual participant-data analysis. The results did not indicate to what extent sex differences in mortality could be attributed to either biological sex or gender. For better understanding of gender inequality, it is essential to integrate data on biological, material, behavioural and societal factors over the life course in men and women. Data harmonization may be a fruitful approach for bringing together strengths of existing cohort studies and identifying different mechanisms across genders, populations and generations. ${ }^{6}$

\section{Conclusion}

This study highlights sex inequality in mortality at older age and the crucial contributions of smoking to excess mortality in men. Future research should investigate variation in life experience between men and women and underlying mechanisms across different societies.

\section{References}

1. World Population Prospects 2019: highlights. New York: Population Division, United Nations. Available: https://population.un.org/wpp/Publications/Files/ WPP2019_Highlights.pdf (accessed 2020 Aug. 27).

2. GBD 2017 DALYs and HALE Collaborators. Global, regional, and national disabilityadjusted life-years (DALYs) for 359 diseases and injuries and healthy life expectancy (HALE) for 195 countries and territories, 1990-2017: a systematic analysis for the Global Burden of Disease Study 2017. Lancet 2018;392:1859-922.

3. Perls T, Frett R. Why women live longer than men. Sci Am. Presents 1998;9:100-3.

4. Alberts SC, Archie EA, Gesquiere LR, et al. The male-female health-survival paradox: a comparative perspective on sex differences in aging and mortality. In: Committee on Population; Division of Behavioral and Social Sciences and Education; National Research Council; Weinstein M, Lane MA, editors. Sociality, Hierarchy, Health: Comparative Biodemography: A Collection of Papers. Washington (DC): National Academic Press; 2014.

5. Rosella LC, Calzavara A, Frank JW, et al. Narrowing mortality gap between men and women over two decades: a registry-based study in Ontario, Canada. BMJ Open 2016;6:e012564.

6. Crimmins EM, Shim H, Zhang YS, et al. Differences between men and women in mortality and the health dimensions of the morbidity process. Clin Chem 2019;65:135-45.

7. Bartley M. Health inequality: an introduction to concepts, theories and methods, 2nd edition. Cambridge (UK): Polity Press, 2016.

8. López-Campos JL, Ruiz-Ramos M, Fernandez E, et al. Recent lung cancer mortality trends in Europe: effect of national smoke-free legislation strengthening. Eur J Cancer Prev 2018;27:296-302.

9. Islami F, Torre LA, Jemal A. Global trends of lung cancer mortality and smoking prevalence. Transl Lung Cancer Res 2015;4:327-38.
10. Rogers RG, Everett BG, Saint Onge JM, et al. Social, behavioral, and biological factors, and sex differences in mortality. Demography 2010;47:555-78.

11. Singh-Manoux A, Guéguen A, Ferrie J, et al. Gender differences in the association between morbidity and mortality among middle-aged men and women. Am J Public Health 2008;98:2251-7.

12. Sanchez-Niubo A, Egea-Cortés L, Olaya B, et al.; ATHLOS Consortium. Cohort profile: the Ageing Trajectories of Health - Longitudinal Opportunities and Synergies (ATHLOS) project. Int J Epidemiol 2019;48:1052-3i.

13. Prina AM, Acosta D, Acosta I, et al. Cohort profile: the 10/66 study. Int J Epidemiol 2017;46:406-6i.

14. Luszcz MA, Giles LC, Anstey KJ, et al. Cohort profile: the Australian Longitudinal Study of Ageing (ALSA). Int J Epidemiol 2016;45:1054-63.

15. Pitsavos C, Panagiotakos DB, Chrysohoou C, et al. Epidemiology of cardiovascular risk factors in Greece: aims, design and baseline characteristics of the ATTICA study. BMC Public Health 2003;3:32.

16. Zhao Y, Hu Y, Smith JP, et al. Cohort profile: the China Health and Retirement Longitudinal Study (CHARLS). Int J Epidemiol 2014;43:61-8.

17. Leonardi M, Chatterji S, Koskinen S, et al. COURAGE in Europe Project's Consortium Determinants of health and disability in ageing population: the COURAGE in Europe Project (collaborative research on ageing in Europe). Clin Psychol Psychother 2014;21:193-8.

18. Steptoe A, Breeze E, Banks J, et al. Cohort profile: the English longitudinal study of ageing. Int J Epidemiol 2013;42:1640-8.

19. Rodríguez-Artalejo F, Graciani A, Guallar-Castillón P, et al. Rationale and methods of the study on nutrition and cardiovascular risk in Spain (ENRICA) [article in Spanish]. Rev Esp Cardiol 2011;64:876-82.

20. Peasey A, Bobak M, Kubinova R, et al. Determinants of cardiovascular disease and other non-communicable diseases in Central and Eastern Europe: Rationale and design of the HAPIEE study. BMC Public Health 2006;6:255.

21. Sonnega A, Faul JD, Ofstedal MB, et al. Cohort profile: the Health and Retirement Study (HRS). Int J Epidemiol 2014;43:576-85.

22. Ichimura H, Shimizutani S, Hashimoto H. JSTAR First Results 2009 Report. RIETI Discussion Paper Series 09-E-047. Tokyo (Japan): Research Institute of Economy, Trade and Industry; 2009. Available: www.rieti.go.jp/jp/publications/dp/09e047. pdf (accessed 2020 Aug. 27).

23. Park JH, Lim S, Lim J-Y, et al. An overview of the Korean Longitudinal Study on Health and Aging. Psychiatry Investig 2007;4:84-95.

24. Börsch-Supan A, Brandt M, Hunkler C, et al. Data resource profile: the Survey of Health, Ageing and Retirement in Europe (SHARE). Int J Epidemiol 2013;42:992-1001.

25. Human development data (1990-2018). New York: United Nations Development Programme. Available: http://hdr.undp.org/en/data (accessed 2020 Aug. 27).

26. Technical notes: calculating the human development indices - graphical presentation. In: Human Development Report 2019: Beyond Income, Beyond Averages, Beyond Today - Inequalities in Human Development in the 21st Century. New York: United Nations Development Programme; 2019. Available: http://hdr.undp.org/ sites/default/files/hdr2019_technical_notes.pdf (accessed 2020 Aug. 27).

27. Maldonado G, Greenland S. Simulation study of confounder-selection strategies. Am J Epidemiol 1993;138:923-36.

28. Burke DL, Ensor J, Riley RD. Meta-analysis using individual participant data: onestage and two-stage approaches, and why they may differ. Stat Med 2017;36:855-75.

29. Lugo A, La Vecchia C, Boccia S, et al. Patterns of smoking prevalence among the elderly in Europe. Int J Environ Res Public Health 2013;10:4418-31.

30. Funatogawa I, Funatogawa T, Yano E. Trends in smoking and lung cancer mortality in Japan, by birth cohort, 1949-2010. Bull World Health Organ 2013;91:332-40.

31. Mattei J, Tamez M, Ríos-Bedoya CF, et al. Health conditions and lifestyle risk factors of adults living in Puerto Rico: a cross-sectional study. BMC Public Health 2018;18:491.

32. Stefler D, Murphy M, Irdam D, et al. Smoking and mortality in Eastern Europe: results from the PrivMort retrospective cohort study of 177,376 individuals. Nicotine Tob Res 2018;20:749-54.

33. Rentería $E$, Jha $P$, Forman $D$, et al. The impact of cigarette smoking on life expectancy between 1980 and 2010: a global perspective. Tob Control 2016;25:551-7.

34. Gambaryan M, Reeves A, Deev A, et al. Effects of tobacco control policy on cardiovascular morbidity and mortality in Russia. Eur J Public Health 2018;28(Suppl 2):14-6.

35. Huxley RR, Woodward M. Cigarette smoking as a risk factor for coronary heart disease in women compared with men: a systematic review and meta-analysis of prospective cohort studies. Lancet 2011;378:1297-305.

36. Nelson JP, McNall AD. What happens to drinking when alcohol policy changes? A review of five natural experiments for alcohol taxes, prices, and availability. Eur J Health Econ 2017;18:417-34.

37. Thun MJ, Carter BD, Feskanich D, et al. 50-year trends in smoking-related mortality in the United States. N Engl J Med 2013;368:351-64.

38. VanderWeele TJ. Mediation analysis: a practitioner's guide. Annu Rev Public Health 2016;37:17-32. 
Competing interests: None declared.

This article has been peer reviewed.

Affiliations: Department of Health Service and Population Research (Wu, Daskalopoulou, Moreno-Agostino, Oram, Prince, Prina), Institute of Psychiatry, Psychology and Neuroscience, King's College London, London, UK; Population Health Sciences (Wu), Newcastle University, Newcastle upon Tyne, UK; Research, Innovation and Teaching Unit (Sanchez Niubo), Parc Sanitari Sant Joan de Déu, Sant Boi de Llobregat, Spain; Centro de Investigación Biomédica en Red de Salud Mental (Sanchez Niubo), Madrid, Spain; Department of Epidemiology and Public Health (Stefler, Bobak), University College London, London, UK

Contributors: Yu-Tzu Wu and Matthew Prina contributed to the conception and design of the work. Albert Sanchez Niubo contributed to the acquisition of data. Yu-Tzu Wu contributed to the analysis and interpretation of data. All of the authors drafted the manuscript, revised it critically for important intellectual content, gave final approval of the version to be published and agreed to be accountable for all aspects of the work.

Funding: This work was supported by the 5 -year Ageing Trajectories of Health: Longitudinal Opportunities and Synergies (ATHLOS) project. The ATHLOS project was funded by the European Union's Horizon 2020 research and innovation programme under grant agreement No 635316. The 10/66 study (10/66): The 10/66 study is supported by the Wellcome Trust (GR066133/GR080002), the European Research Council (340755), US Alzheimer's Association, the World Health Organization (WHO), FONDACIT (Venezuela) and the Puerto Rico State Government, and the Medical Research Council (MR/K021907/1 to A.M.P.). The authors gratefully acknowledge the work of the 10/66 Dementia Research Group, who provided data for this article. The Australian Longitudinal Study of Ageing (ALSA): The ALSA study was supported by grants from the South Australian Health Commission, the Australian Rotary Health Research Fund, the US National Institute on Aging (Grant No. AG 08523-02), the Office for the Ageing (South Australia [SA]), Elderly Citizens Homes (SA), the National Health and Medical Research Council (NH\&MRC 22922), the Premiers Science Research Fund (SA) and the Australian Research Council (DP0879152; DP130100428). The authors gratefully acknowledge the work of the project team at the Flinders Centre for Ageing Studies, Flinders University, who provided data for this article. The ATTICA study: The ATTICA study is supported by research grants from the Hellenic Cardiology Society (HCS2002) and the Hellenic Atherosclerosis Society (HAS2003). The authors gratefully acknowledge the work of the project team at the Harokopio University, who provided data for this article. The China Health and Retirement Longitudinal Study (CHARLS): The CHARLS study has received critical support from Peking University, the National Natural Science Foundation of China, the Behavioral and Social Research Division of the National Institute on Aging, and the World Bank. The authors gratefully acknowledge the work of the project team at Peking University, who provided data for this article. Collaborative Research on Ageing (COURAGE) in Europe: The COURAGE study was supported by the European Community's Seventh Framework Programme (FP7/2007-2013) under grant agreement number 223071 (COURAGE in Europe). Data from Spain were also collected with support from the Instituto de Salud Carlos III-FIS research grant numbers PS09/00295, PS09/01845, $\mathrm{PI} 12 / 01490, \mathrm{PI} 13 / 00059, \mathrm{PI} 16 / 00218$ and PI16/01073; the Spanish Ministry of Science and Innovation ACI-Promociona (ACI2009-1010); the European Regional Development Fund (ERDF) "A Way to Build Europe" grant numbers PI12/01490 and PI13/00059; and by the Centro de Investigación Biomédica en Red de Salud Mental, Instituto de Salud Carlos III. Data from Poland were collected with support from the Polish Ministry for Science and Higher Education grant for an international cofinanced project (number 1277/7PR/UE/2009/7, 2009-2012) and JagielIonian University Medical College grant for project COURAGE-POLFUS
(K/ZDS/005241). The authors gratefully acknowledge the work of COURAGE researchers, who provided data for this article. The SeniorsENRICA (the Study on Nutrition and Cardiovascular Risk in Spain): The Seniors-ENRICA cohort was funded by an unconditional grant from Sanofi-Aventis, the Ministry of Health of Spain, FIS grant 12/1166 (State Secretary for R+D and FEDER-FSE) and the Centro de Investigación Biomédica en Red de Epidemiología y Salud Pública, Instituto de Salud Carlos III. The authors gratefully acknowledge the work of the project team at the Universidad Autónoma de Madrid, who provided data for this article. The English Longitudinal Study of Ageing (ELSA): ELSA is supported by the US National Institute of Aging, the National Centre for Social Research, the University College London and the Institute for Fiscal Studies. The authors gratefully acknowledge the UK Data Service and University College London, who provided data for this article. The Health, Alcohol and Psychosocial factors In Eastern Europe (HAPIEE) study: The HAPIEE study was supported by the Wellcome Trust (grant numbers WT064947, WT081081), the US National Institute of Aging (grant number 1RO1AG23522)and the MacArthur Foundation Initiative on Social Upheaval and Health. The authors gratefully acknowledge the work of the project teams at University College London, the National Institute of Public Health in Prague, the Jagiellonian University Medical College in Krakow and the Kaunas University of Medicine, who provided data for this article. Health and Retirement Study (HRS): The HRS study is supported by the National Institute on Aging (grant no. NIA U01AG009740) and the Social Security Administration, and is conducted by the University of Michigan. The authors gratefully acknowledge the University of Michigan, who provided data for this article. The Japanese Study of Aging and Retirement (JSTAR): The JSTAR is conducted by the Research Institute of Economy, Trade and Industry (RIETI), the Hitotsubashi University, and the University of Tokyo. The authors gratefully acknowledge the RIETI, who provided data for this article. The Korean Longitudinal Study of Ageing (KLOSA): The KLOSA study is funded by the Korea Employment Information Service (KEIS) and was supported by the Korea Labor Institute's KLOSA Team. The authors gratefully acknowledge the KEIS, who provided data for this article. The Survey of Health, Ageing and Retirement in Europe (SHARE): The SHARE study is funded by the European Commission through FP5 (QLK6-CT-2001-00360), FP6 (SHARE-I3: RIICT-2006-062193, COMPARE: CIT5-CT-2005-028857, SHARELIFE: CIT4CT-2006-028812) and FP7 (SHARE-PREP: N²11909, SHARE-LEAP: N²27822, SHARE M4: №261982). Additional funding from the German Ministry of Education and Research, the Max Planck Society for the Advancement of Science, the US National Institute on Aging (U01_ AG09740-13S2, P01_AG005842, P01_AG08291, P30_AG12815, R21_ AG025169, Y1-AG-4553-01, IAG_BSR06-11, OGHA_04-064, HHSN271201300071C) and from various national funding sources is gratefully acknowledged (see www.share-project.org). The funders had no role in study design, data collection, data analysis, data interpretation, writing of the report or decision to submit for publication.

Copyright: This is an Open Access article distributed in accordance with the terms of the Creative Commons Attribution (CC BY 4.0) licence, which permits others to distribute, remix, adapt and build upon this work, for commercial use, provided the original work is properly cited. See: http://creativecommons.org/licenses/by/4.0/.

Data sharing: Documentation and metadata of the ATHLOS harmonization process can be accessed online (https://github.com/athlosproject/athlos-project.github.io). The original cohort data are publicly available for CHARLS, HRS, ELSA, KLOSA, MHAS and SHARE, or can be accessed by contacting the management teams of the cohort studies on reasonable request.

Accepted: Aug. 26, 2020

Correspondence to: Yu-Tzu Wu, yu-tzu.wu@kcl.ac.uk 